Article

\title{
An Evaluation Method of Green Development for Chemical Enterprises
}

\author{
Yitong Chen ${ }^{1}$, Shanying Hu ${ }^{1, *}$, Dingjiang Chen ${ }^{1}$, Hongxuan Zhai ${ }^{2}$, Shutao Bao ${ }^{2}$ \\ and Tianbao $\mathrm{Lv}^{2}$ \\ 1 Center for Industrial Ecology, Department of Chemical Engineering, Tsinghua University, Beijing 100084, \\ China; cyt17@mails.tsinghua.edu.cn (Y.C.); chendj@mail.tsinghua.edu.cn (D.C.) \\ 2 Shandong Lubei Enterprise Group General Company, Binzhou 256600, China; 13305433028@163.com (H.Z.); \\ baoshutao@126.com (S.B.); wdlvtianbao@163.com (T.L.) \\ * Correspondence: hxr-dce@tsinghua.edu.cn; Tel.: +86-10-62794513
}

Received: 15 October 2019; Accepted: 9 November 2019; Published: 18 November 2019

check for updates

\begin{abstract}
Chemical enterprises in China make important contributions to daily life and the national economy. Since "green development" has been treated as one of the most important developmental strategies in China, scientifically evaluating the level of green development is extremely important for chemical enterprises. In this study, a systematic evaluation method is proposed for chemical enterprises by analytic hierarchy process (AHP). The key to this evaluation method is a new comprehensive indicator, the Green Development Degree (GDD). As an example, Shandong Lubei Enterprise, that has the process of phosphogypsum to sulfuric acid and cement (PSC), is analyzed by GDD. The results show that GDD would increase with the improvement of the PSC process's green evolution. When compared with the national average level, the GDD of the case enterprise increases from 50 to 133. In addition, experience regarding the green development for chemical enterprises is proposed. This study aims to guide the green development of chemical enterprises, help enterprise groups to assess subsidiary corporations and adjust improvement measures, and achieve the national macro-control of chemical enterprises.
\end{abstract}

Keywords: green development; evaluation index system; comprehensive evaluation; chemical enterprise; phosphogypsum to sulfuric acid and cement (PSC)

\section{Introduction}

The chemical industry is an important part of the manufacturing industry [1]. As a basis of construction, chemical industry products have provided many conveniences for daily life and have been an indispensable part of society [2]. With the rapid growth of the economy, chemical industries have also achieved great developments in the 21st century [3]. However, prominent problems have concomitantly been increasing, such as low corporate income, excessive consumption of resources, and the discharge of wastes [4].

Therefore, in the 1980s, people began to pay attention to issues related to green production and green manufacturing. In 1998, P.T. Anastas and J.C. Waner proposed the 12 principles of green chemistry [5]. During the past several decades, environmental protection, which can coordinate relationships among the environment, resources, energy, and economy, was customized as a basic national policy in China [6]. This policy not only indicates that the green development strategy has already risen to an institutional arrangement, but also emphasizes the green development of chemical enterprises. In 2009, the World Climate Conference-3 established a great international impact on green development and the national economy [7]. A growing concern regarding the greenness of chemical enterprises has 
clearly occurred [8]. Thus, there is an urgency among the chemical enterprises in China to adhere to green development and achieve further improvements in terms of environmental protection.

To compare and evaluate the greenness of different production processes for chemical enterprises, a number of indicators were created. Among these indicators, atom economy and $\mathrm{E}$ factor are the oldest and the simplest green chemical indicators [9], which also lay the foundation for many subsequent similar mass-based indicators [10].

Atom economy is a theoretical indicator, and an advantage of atom economy is that it can occur independently of experimentation [11]. Thus, the amount of waste that will be generated during production processes can be rapidly predicted through the use of atom economy. However, a disadvantage of atom economy is also encountered because most reactions are in fact performed using significant stoichiometric excesses [9]. Consequently, atom economy cannot account for practical production.

As for the E factor, the actual amount of waste that is produced from all auxiliary components in the process can be taken into consideration. Additionally, the $\mathrm{E}$ factor can facilitate a holistic assessment of processes because it can be applied to a multistep process [11]. However, only the waste part can be considered in the $\mathrm{E}$ factor by definition, and thus, this indicator can never be used as a systematic evaluation method [12].

In addition to atom economy and the $\mathrm{E}$ factor, a variety of alternative metrics for measuring the greenness of processes have been proposed, such as the reaction mass efficiency [13] and the effective mass yield [14]. These two indicators are similar to atom economy, and thus, they cannot easily be used in reality.

For actual processes, mass intensity [9] and process mass intensity [11] take the yield, solvent, and reagent into account, and can be more broadly understood. This indicator mainly focuses on reducing the costs of the raw material input. However, these indicators' specific concerns regarding health, safety, the environment, and the waste produced are not included [15].

There are some assessment methods that refer to the economy, resource, and environment to reflect the sustainability of production in the chemical industry. For example, some criteria were selected by Patel et al. to help establish a set of sustainability evaluation methods [16]. However, a suitable and concise comprehensive indicator for the chemical enterprises is still used as a requirement [17], with which the greenness of enterprises can be appropriately evaluated.

To address the above challenges, this paper proposes a new systematic indicator, the Green Development Degree (GDD), for the evaluation of greenness for chemical enterprises, which is based on four key aspects of the production process. Then, the evolution of the core production process of phosphogypsum to sulfuric acid and cement (PSC) is analyzed using GDD. The influences of this process evolution on economy, resource, energy, and environment are also systematically demonstrated. Finally, suggestions are provided based on the evaluation of the PSC case using GDD in this research, which are useful for promoting the green development of other enterprises.

\section{Methods}

\subsection{Material Flow Analysis}

The material flow analysis (MFA) method was used to provide a systematic assessment of the material flows in each production process of the enterprise in detail [18]. This method connects the sources, the processes, and the intermediate and final sinks of a material [19]. Moreover, this method can draw conclusions from different perspectives concerning issues, such as resources and the environment, and provide convenience to evaluate various indicators of production processes [20]. The results of MFA can be controlled by the material balance because of the conservation of matter [18]. This is the characteristic of MFA that makes it a tool in resource and environmental management [19]. 


\subsection{Analytic Hierarchy Process}

In the last few decades, the analytic hierarchy process (AHP) has been applied to a number of practical problems [21]. The AHP is a method for analyzing and formulating decisions [22]. The AHP is established based on subjective inputs for multiple criteria and used to develop a benefit measurement model [23]. By translating the inputs into scores, AHP can be used to evaluate influences on each of the alternatives [22]. Moreover, the AHP can make complex decision processes rational in a systematic manner by combining all available information [21]. Because it is intuitive and flexible, the AHP is routinely used for making major decisions by enterprises and governments [21].

\subsection{Evaluation Index of Enterprise Green Development}

To measure the benefit of enterprises that have applied the green development strategy, an evaluation index that is not only a kind of data combination but also an efficient and reasonable system to show the level of the green development of enterprises is necessary [24]. Due to the results of some previous experiments and the features of enterprises, the evaluation index ought to be constructed under the following five aspects [25-28].

\section{- $\quad$ Objective}

The index must be able to respond efficiently and significantly to the features and designs of the enterprises, and it will fully show the differences between the enterprises that adopted the green development strategy and the traditional enterprises.

- Systematic

An enterprise is not only an isolated industrial chain, but also a complicated system containing several sections, such as the resources, environment, and economy. All these sections should be considered to construct the evaluation index.

- $\quad$ Scientific

The significance of the index should be practical, the data sources should be accurate, and the methods should be appropriate to effectively show the results of evolution.

\section{- Comparable}

The index must enable intercomparison and intracomparison of enterprises to evaluate and analyze their specific conditions properly and show the changes in the green development process.

\section{- Operability}

The index should provide not only the information for the enterprises, but also the reliable methods to help them improve their green development process.

Since many indicators have been established based on different key points, a comprehensive index for enterprises, the GDD, is proposed to evaluate greenness based on these five aspects. According to the 12 principles of green chemistry [5], the comprehensive evaluation index system for chemical enterprise is established in this paper. The descriptions of target layer, criterion layer, index layer, and index category are shown in Table 1. The determination of indices is a combination of the comprehensive research on the chemical enterprises and other industries [29-36].

In this research, the AHP is used to determine the weight of indices (Table 1). These four index weights are $0.329,0.200,0.329$, and 0.142 , and the random consistency rate $C R=0.023<1$, indicating that the judgement matrix is acceptable. For the tertiary indices, it can determine the weight by the equipartition. 
Table 1. Evaluation index system of the Green Development Degree (GDD)

\begin{tabular}{ccccc}
\hline Target & Criterion & Weight & Index & Category \\
\hline \multirow{7}{*}{ GDD } & Economy & 0.329 & Gross profit percentage & Positive \\
\cline { 2 - 5 } & Resource & 0.200 & $\begin{array}{c}\text { Substance efficiency } \\
\text { Resource productivity }\end{array}$ & $\begin{array}{c}\text { Positive } \\
\text { Positive }\end{array}$ \\
\cline { 2 - 5 } & Environment & 0.329 & $\begin{array}{c}\text { Waste gas emission } \\
\text { Wastewater emission }\end{array}$ & $\begin{array}{c}\text { Negative } \\
\text { Negative } \\
\end{array}$ \\
\cline { 2 - 5 } & Energy & 0.142 & Integrated utilization of solid waste (Industrial residue) & Positive \\
\hline
\end{tabular}

\subsubsection{Economic Index}

The economic index is identified as a prerequisite in the GDD, since the development of the enterprise is inseparable from economic support. It is essential that a good economic foundation is the driving force for the continued development of enterprises. When enterprises shift focuses on implementing the green development strategy, it is necessary to consider economic returns. Based on the above considerations, the gross profit percentage is designed under the economic index, which directly reflects the profitability of the enterprise. The gross profit percentage is defined as the difference between net sales and the cost of goods sold divided by net sales.

\subsubsection{Resource Index}

Additionally, the resource index also plays an important role in the GDD. Since the 3R principle of circular economy, which means reduce, recycle and reuse, was proposed in 2002, it has been a guide for enterprises to emphasize the least ecological cost but the largest improvement of efficiency in terms of resources [37]. In addition, the Fifth Plenary Session of the 17th Central Committee of the Communist Party of China (CPC) clearly stated that it is necessary to promote the development of a circular economy with the goal of improving the efficiency of resource productivity $[38,39]$. According to these considerations, the following two indices are selected for analysis and evaluation.

\section{(1) Substance efficiency}

Substance efficiency is used to evaluate the utilization of elements in production processes. In this research, element utilization and the elemental cycle index are used to describe the substance efficiency.

Element utilization was used to describe resource benefits. Element utilization is defined in Equation (1):

$$
\text { Element utilization }=\sum_{i} M_{\text {outi }} X_{i} /\left(\sum_{j} M_{\text {inj }} X_{j}\right) \times 100 \%
$$

$M_{\text {out } i}$ is the mass of product $i$ leaving the system, $X_{i}$ is the mass fraction of the element in the product $i, M_{i n j}$ is the mass of the raw material j entering the system, and $X_{j}$ is the mass fraction of the element in the raw material $j$.

The elemental cycle index indicates the degree of recycling of an element in production. The elemental cycle index is defined as the percentage of the element in the recycled material in the total amount of that element in the input system. The formula is shown in Equation (2):

$$
\text { Elemental cycle index }=\sum_{i} M_{c i} X_{i} /\left(\sum_{j} M_{i n j} X_{j}\right) \times 100 \%,
$$

$M_{c i}$ is the mass of circulating material $i$ in the system, $X_{i}$ is the mass fraction of this element in circulating material $i, M_{i n j}$ is the mass of material $j$ that enters the system with this element, and $X_{j}$ is the mass of that element contained in this mass $j$ fraction.

It must be noted that these indices are designed for key elements in processes and not random elements. 


\section{(2) Resource productivity}

Resource productivity is a widely used index for evaluating the development level of a circular economy, and it is also an important index to reflect the achievement of a resource-saving and environmentally friendly society $[40,41]$. The resource productivity represents the economic value created by a unit of resources, that is, the ratio of industry value added to the input of raw materials.

In brief, the resource index in the GDD can help enterprises to investigate the utilization of resources, which is useful to adjust developing strategies.

\subsubsection{Environment Index}

There are "three wastes" in production, which are waste gas, wastewater and industrial residue. It is necessary for enterprises to achieve three types of waste emission reduction when adopting green development strategies. Moreover, because it contains a variety of wastes such as $\mathrm{SO}_{2}, \mathrm{NO}_{X}$, coal ash, gypsum, and others, the environment index should be established by the specific circumstance.

\subsubsection{Energy Index}

The utilization of energy correctly to reduce the environmental cost and achieve green development is of great significance. Therefore, the energy index is designed as an important basis in the GDD. Energy consumption of ten-thousand-yuan industrial added value is selected to evaluate the energy consumption of enterprises.

\subsubsection{Green Development Degree}

To consider the results of these indices, a distinct problem is observed. Some results are presented as a percentage, while other results are direct numbers. Thus, the results of the national average, industrial average, and industrial leading value concerning these indices were chosen as norms. In this way, the indices in the GDD $\left(G_{i}\right)$ can be presented as Equation (3):

$$
G_{i}=R_{i} / N_{i} \times 100,
$$

In Equation (3), $R_{i}$ is the result of indices for enterprises, and the $N_{i}$ is the norm of the index. For further calculation, the ratio is multiplied by 100 .

Additionally, as shown in Table 1, there are clearly two parts of the indices in the GDD, which contain positive indices, such as the gross profit percentage, substance efficiency and resource productivity, and negative indices, such as environment indices and the energy index. To unify these indices, the negative index results are reciprocal when they are put into the GDD.

From the above, the GDD is defined as Equation (4):

$$
G D D=\left(\prod_{i} I_{i}^{k_{i}}\right)^{1 / \sum_{i} k_{i}},
$$

$I_{i}$ is the processed result of the index $i$, and $k_{i}$ is the weight of the index $i$. The weighted geometric means can consider the weight of each index and make different orders of magnitude results effective. Simultaneously, the weighted geometric mean can detect the difference between enterprises with better average results and a better extremum than a weighted average.

The GDD can be used to analyze the comprehensive influences on enterprises. There are three circumstances based on the results of GDD:

When GDD $<100$, the comprehensive evaluation of enterprise is less than the norm, which means there is still room for improvement. For example, if the national average was used as the norm, GDD $<100$ would mean that the enterprise did not match the national average level.

When GDD $=100$, the enterprise is recognized up to the norm. Additionally, it should be noted that if the industrial leading value was selected as the norm, the enterprise would have been the most advanced. 
When GDD > 100, the enterprise is better than the norm. In other words, the enterprise surpasses the average for the enterprise when comprehensive aspects are taken into consideration. This situation only occurs when the average is the norm because the industrial leading value must be the best value.

In conclusion, the larger the GDD, the better the enterprise is, when it is evaluated under the same type of norm.

\section{Case Study}

The chemical industry is an indispensable part of development in China. With the rapid evolution of chemical enterprises, green development has gradually received great attention. In this research, an enterprise, which is a typical eco-enterprise of the Asia-Pacific organization of United Nations Environment Programme (UNEP) in China and the first eco-enterprise demonstration in China, has been taken as an example. The green evolution processes of the enterprise are described as follows.

The enterprise established a sulfuric acid plant in 1977, which was placed in production in 1984, established phosphogypsum to sulfuric acid and cement (PSC) technology in 1986 [42], and used waste produced from phosphate fertilizers to produce co-produced sulfuric acid. In PSC, the sulfuric acid, which is produced by phosphogypsum, is returned to extraction and filtration for further use to manufacture phosphate fertilizers. The created of PSC revealed the method of waste reuse that was generated from phosphate fertilizers, and no waste was discharged during this production process [43]. Subsequently, in 1990, another ecological production technology was established to include waste slag and salt gypsum in the PSC process. Subsequently, clean power generation was established and combined with salt and alkali. Slag, which was generated from clean power generation, was included in the PSC process [44-46]. Then, the enterprise completed the research and development of titanium dioxide cleaner production technology and included titanium gypsum into the PSC process in 2014 [47-49]. Finally, in 2016, the enterprise cooperated with other factories to dispose of alkylated waste acids.

The PSC process, which can turn waste products into raw material for another product, is clearly a significant core process. An efficient, recycling mode of production has been formed based on the PSC process. Therefore, the PSC process is a focus to analyze and discuss the influence on economy, resource, environment, and energy.

The evolution of the PSC process can be divided into eight stages to clearly analyze its development processes.

In stage 1, in 1986, rock phosphate was ground in water and then subjected to extraction filtration, followed by neutralization and concentration for the production of phosphate fertilizer (Figure 1a). Sulfuric acid was supplied by the sulfur-burning sulfuric acid process in this stage. Subsequently, to address the problem of accumulated phosphogypsum, the technology of using phosphogypsum to produce sulfuric acid cement was developed. In stage 2, in 1987, phosphogypsum, generated by the production of phosphate fertilizer, was decomposed and calcined into a cement clinker and $\mathrm{SO}_{2}$. Sulfur dioxide was then used to produce sulfuric acid, and the produced sulfuric acid was returned to manufacture phosphate fertilizer.

Subsequently, this enterprise was scaled up (stage 3), solving the problems of slag (stage 4) and salt gypsum (stage 5) in 1991. In stage 6, from 1997 to 2005, the scale of production expanded from the 3-4-6 project (stage 6.1, annual output of 30,000 tons of ammonium phosphate, 40,000 tons of sulfuric acid and 60,000 tons of co-produced cement) to the 30-40-60 project (stage 6.4, an annual output of 300,000 tons of ammonium phosphate, 400,000 tons of sulfuric acid and 600,000 tons of co-produced cement). 


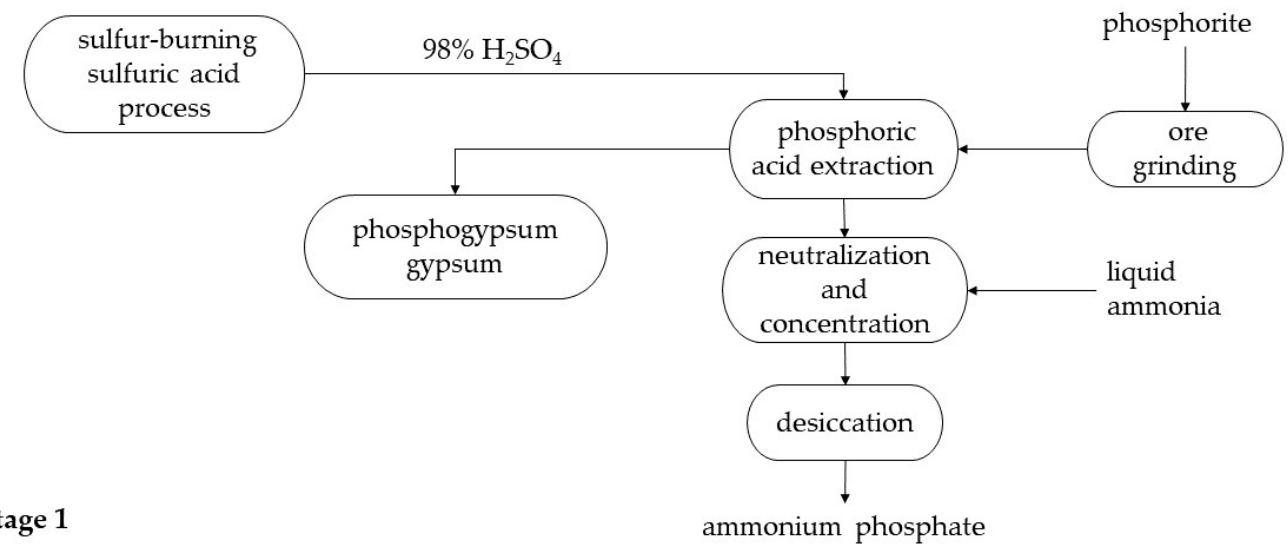

(a)

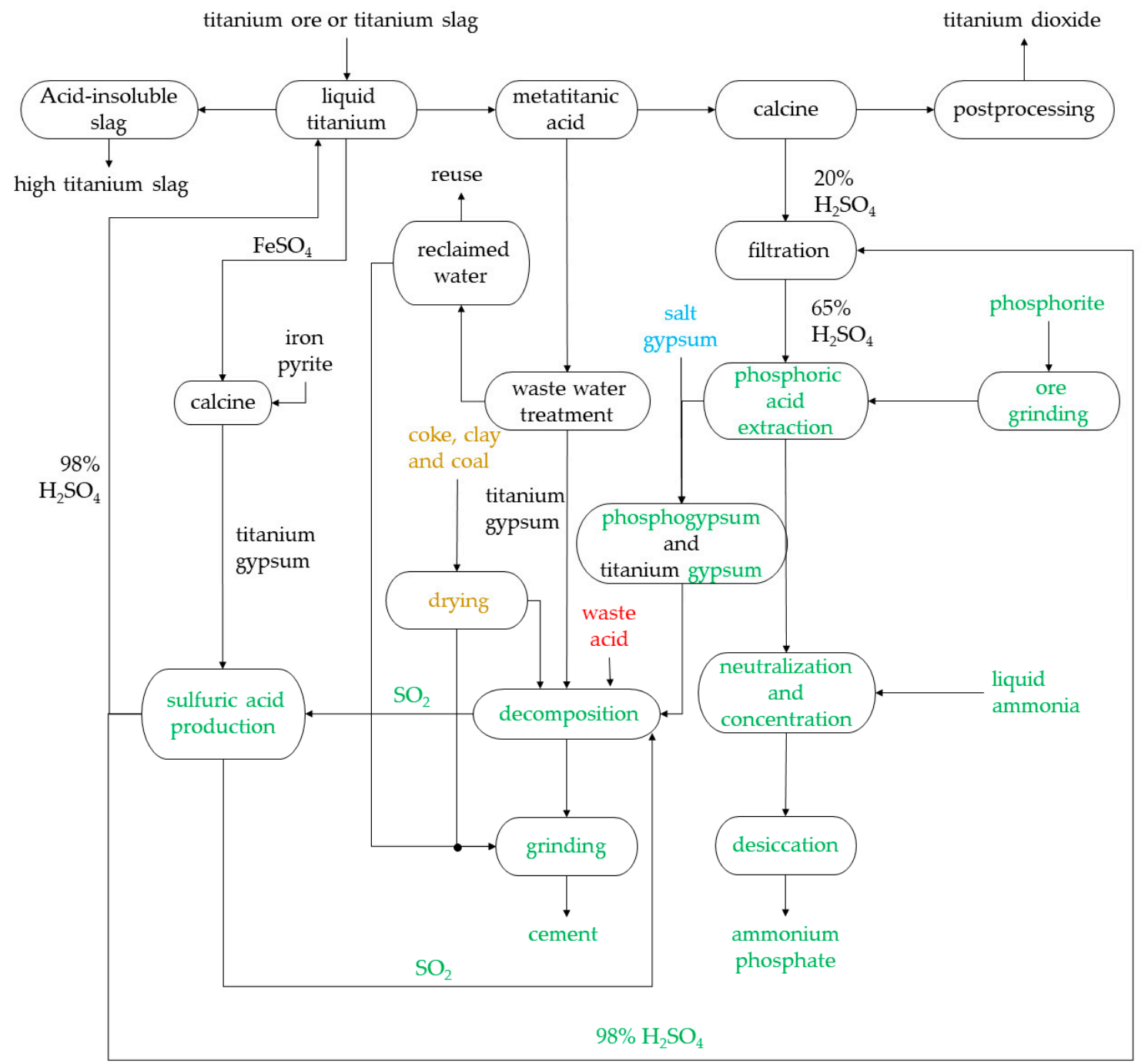

Stage 2 and 3:

Stage 7:

(b)
Stage 5、6.1、6.2、6.3 and 6.4: $\square+\square+$

Stage 8 :

Figure 1. Evolution of the PSC process. PSC: phosphogypsum to sulfuric acid and cement. 
Based on the PSC process, titanium dioxide production technology was researched in stage 7 in 2014, using titanium ore as raw material and the titanium dioxide acid hydrolysis method. Titanium gypsum is included in the PSC process to achieve the clean production of titanium dioxide and the co-production of titanium dioxide, sulfuric acid, ammonium phosphate, and gypsum.

Finally, in stage 8, in 2016, the enterprise cooperated with other factories to co-treat alkylated waste sulfuric acid. The alkylated waste sulfuric acid, which is black, sticky, and strongly amyctic, is produced in the alkylation process of petroleum and contains approximately $3 \%$ to $8 \%$ hydrocarbon compounds. Additionally, the alkylated waste sulfuric acid is extremely harmful to people, animals, and the environment. For this reason, it is important to deal with it properly (Figure 1b).

The evolution of PSC process is shown in Figure 1.

\section{Results and Discussion}

\subsection{Results of the Green Development Degree}

By implementing the green development strategy, the enterprise has clearly achieved a variety of improvements. The specific results of the indices have been enumerated to analyze the influence on economy (gross profit percentage), resource (element utilization, element cycle index, resource productivity), environment (integrated utilization of key resources, waste gas emission), and energy (energy consumption), as shown in Table 2.

Table 2. Variations based on the green evolution of the case enterprise.

\begin{tabular}{|c|c|c|c|c|c|c|c|c|c|c|c|}
\hline Stage & 1 & 2 & 3 & 4 & 5 & 6.1 & 6.2 & 6.3 & 6.4 & 7 & 8 \\
\hline utilization of $\mathrm{P} / \%$ & 88.66 & 88.66 & 92.71 & 92.71 & 92.71 & 93.09 & 95.04 & 94.73 & 95.48 & 96.86 & 96.86 \\
\hline resource productivity/yuan $\cdot \mathrm{t}^{-1}$ & 354.2 & 438.5 & 453.4 & 453.4 & 453.4 & 453.4 & 464.2 & 482 & 484 & 853.6 & 871.2 \\
\hline $\mathrm{SO}_{2}$ emission/t -billion yuan ${ }^{-1}$ & 20.15 & 1.544 & 1.431 & 1.431 & 1.78 & 0.8511 & 0.7699 & 0.918 & 0.7409 & 0.2925 & 0.2866 \\
\hline $\mathrm{CO}_{2}$ emission/t $\cdot$ billion yuan ${ }^{-1}$ & 3370 & 15,272 & 13,746 & 13,746 & 13,201 & 13,201 & 11,942 & 14,238 & 12,641 & 5253 & 5147 \\
\hline $\begin{array}{l}\text { energy consumption/t.ten } \\
\text { thousand yuan }{ }^{-1}\end{array}$ & 1.773 & 1.614 & 1.625 & 1.625 & 2.051 & 2.051 & 1.967 & 1.936 & 2.544 & 1.651 & 1.954 \\
\hline
\end{tabular}

According to the characteristics of the case enterprise, the weight of the secondary indices exhibits weight equipartition. Additionally, in this research, the national average, industrial average, and industrial leading value are chosen as the norms. As shown in Figure 2, the trend of the GDD is similar even under different norms.

For the national average being the norm, the enterprise was not up to standard in the early stages, which means that the GDD was less than 100; at the mid-term, the enterprise basically matched the national average level; then as the green evolution proceeded (Figure 2), the GDD was much greater than 100, and this enterprise achieved greenness on comprehensive aspects compared to the national average.

Referring to the industrial average (Figure 2), when it is chosen as the norm, the case enterprise is far better than the industrial average level, except in stage 1 . This finding indicates that the chemical industrial average is less than the national average in general, which emphasizes the importance of chemical enterprises to adopt the green development strategy. Additionally, these results show that an enterprise can be better in greenness than average when it has a green production line.

For the industrial leading value, as shown in Figure 2, the enterprise then became increasingly closer to the leading level through the green evolution. Before the enterprise took steps towards greenness, in stage 1, it was far away from the leading value. Once the enterprise adopted these measures, it became progressive. 


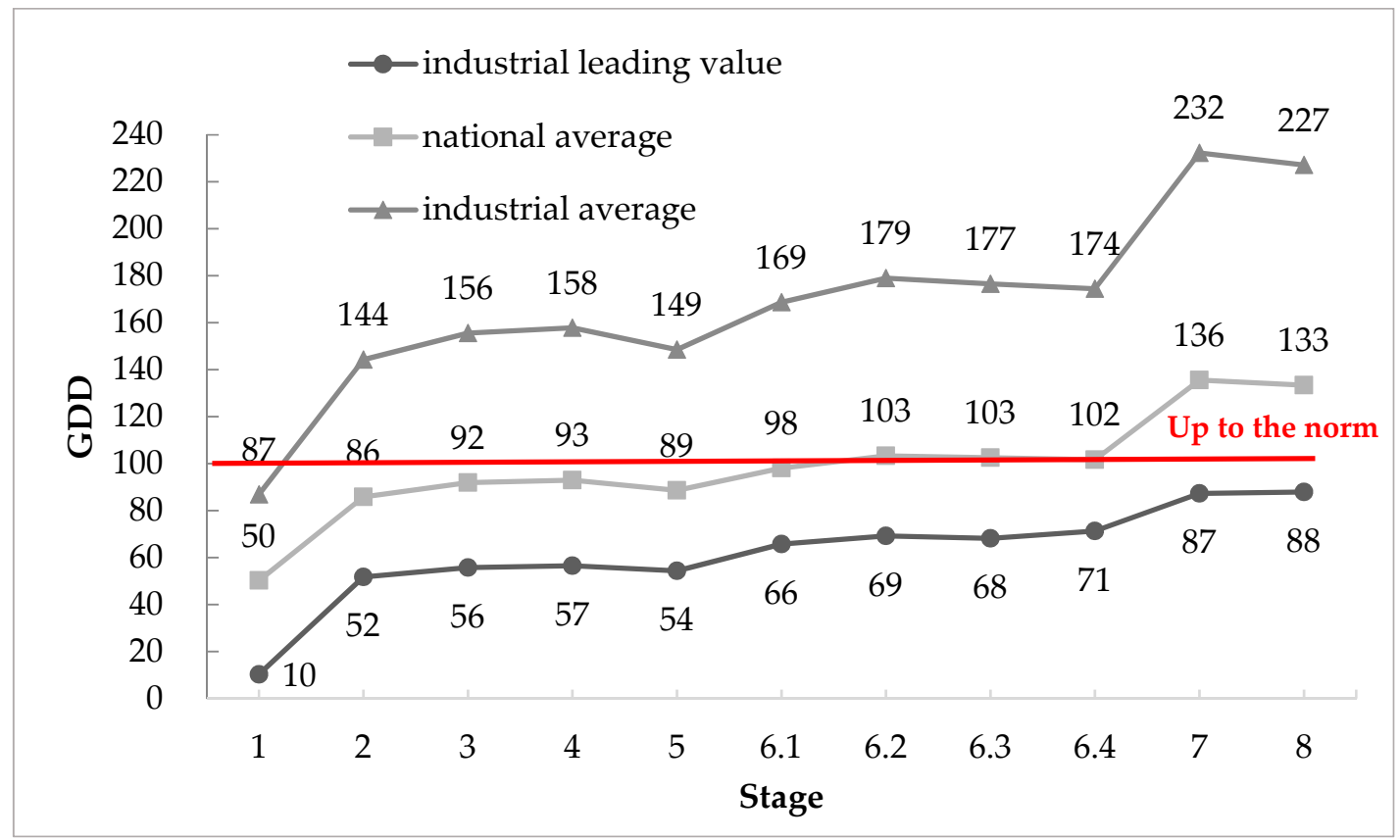

Figure 2. Green Development Degree of PSC.

Because the trends of these results were similar, the GDD based on the national average was selected for further analysis. Besides, the results of indices based on the national average $\left(\mathrm{I}_{\mathrm{i}}\right)$ are shown in Table 3. It is worth noting that the negative index results have been reciprocal in Table 3.

Table 3. Results of indices based on the national average.

\begin{tabular}{cccccccccccc}
\hline Stage & $\mathbf{1}$ & $\mathbf{2}$ & $\mathbf{3}$ & $\mathbf{4}$ & $\mathbf{5}$ & $\mathbf{6 . 1}$ & $\mathbf{6 . 2}$ & $\mathbf{6 . 3}$ & $\mathbf{6 . 4}$ & $\mathbf{7}$ & $\mathbf{8}$ \\
\hline $\mathrm{I}_{\text {gross profit percentage }}$ & 149.5 & 194.8 & 223.8 & 223.8 & 223.8 & 253.5 & 278.3 & 289.0 & 292.7 & 310.0 & 313.2 \\
$\mathrm{I}_{\text {utilization of } \mathrm{P}}$ & 155.5 & 155.5 & 162.6 & 162.6 & 162.6 & 163.3 & 166.7 & 166.2 & 167.5 & 169.9 & 169.9 \\
$\mathrm{I}_{\text {resource productivity }}$ & 12.15 & 15.04 & 15.55 & 15.55 & 15.55 & 15.55 & 15.92 & 16.53 & 16.60 & 29.27 & 29.88 \\
$\mathrm{I}_{\text {SO2 emission }}$ & 13.45 & 175.5 & 189.4 & 189.4 & 152.2 & 318.4 & 351.9 & 295.2 & 365.7 & 928.1 & 944.3 \\
$\mathrm{I}_{\text {CO2 emission }}$ & 34.60 & 7.636 & 8.484 & 8.484 & 8.834 & 8.834 & 9.766 & 8.190 & 9.225 & 22.20 & 22.66 \\
$\mathrm{I}_{\text {integrated utilization of solid waste }}$ & 0 & 157.6 & 158.3 & 169.9 & 169.1 & 169.1 & 163.4 & 166.6 & 164.1 & 164.2 & 163.7 \\
$\mathrm{I}_{\text {energy consumption }}$ & 34.96 & 38.42 & 38.16 & 38.16 & 30.22 & 30.22 & 31.52 & 32.02 & 24.37 & 37.54 & 31.73 \\
\hline
\end{tabular}

According to the analysis of the evolution of the PSC process, the results for the GDD are shown in Figure 2. It can be seen that the results increased from 50 to 133 with the development of the PSC process.

According to Equation (3), the larger the GDD, the better the greenness possessed by an enterprise. In this case, the GDD basically increased with evolution.

The contribution of each index to the GDD is shown in Figure 3, the natural logarithm of the GDD is considered. As evidenced in Figure 3, economy provided the greatest contribution to the GDD, which indicated that the case enterprise had a better economic income than the national average. For the environment indices, it gradually played an important part in the GDD, and the integrated utilization of the solid waste of the enterprise accounted for a major proportion, indicating a great achievement in this respect. Additionally, the contribution of $\mathrm{SO}_{2}$ emission was necessary, while the $\mathrm{CO}_{2}$ emission was expected to improve. For the resource indices, it had been important for the comprehensive evaluation in early stages. However, with the progress of technology, the advantage of the resource for the enterprise became less tangible. Energy consumption is the aspect that the enterprise should improve because it was only good for the GDD in stage 1. In brief, for the case enterprise, energy consumption would be superior for enhancing the production efficiency. 


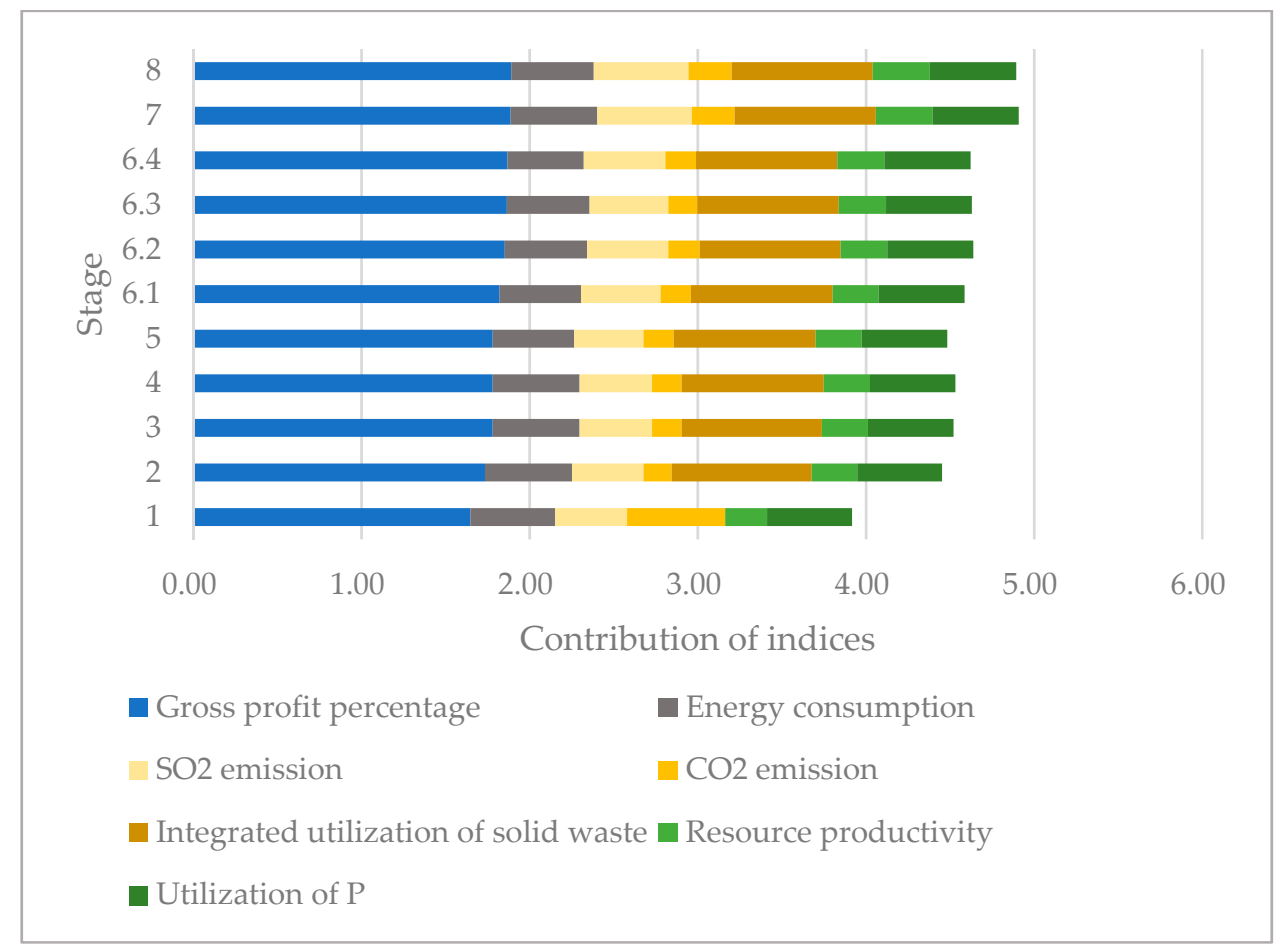

Figure 3. Contribution of the indices contained in the GDD.

For the case, the enterprise implemented a series of green evolutions, which eventually formed an ecological industrial chain with economic growth, resource conservation, and environmental friendliness. In this research, improvement of the case was analyzed from various aspects to show how an enterprise can set up an effective and beneficial method to implement the green development strategy.

\subsection{Analysis of the Economy Contribution}

The annual value of production is the total value of all products produced by an enterprise in one year. In this research, to avoid the influence of the price changes of products and the time value of money (the value-added effect of money after a period of time), the prices of these productions in 2015 were selected as a standard to estimate the annual output value, as well as the cost of raw materials.

As shown in Figure 4, that the annual output value of the enterprise was growing from 24.7 million yuan to 2474.48 million yuan, it can be seen that the case enterprise was in a state of increasing annual output value. According to the research, there were two main reasons. One was the rising product volume; the other was the increasing product range with gradual progress. The benefits of co-treating process waste acid were not evident.

To clearly demonstrate economic growth, the annual rate of the economic growth curve is plotted in Figure 4. Clearly, the scale of expanded production provides a quick way to increase economic income.

The gross profit percentage of the company is shown in Table 2. First, from stage 1 to stage 2, the increase in gross profit percentage was due to the development of the PSC process and the addition of new product cement. Then, from stage 2 to stage 3, the increase in gross profit percentage was caused by the expanded scale of production, which also occurred in stage 6 . In stage 7 , the addition of titanium dioxide resulted in the increase. In stage 8 , a slight growth occurred from co-processing of waste acid. 


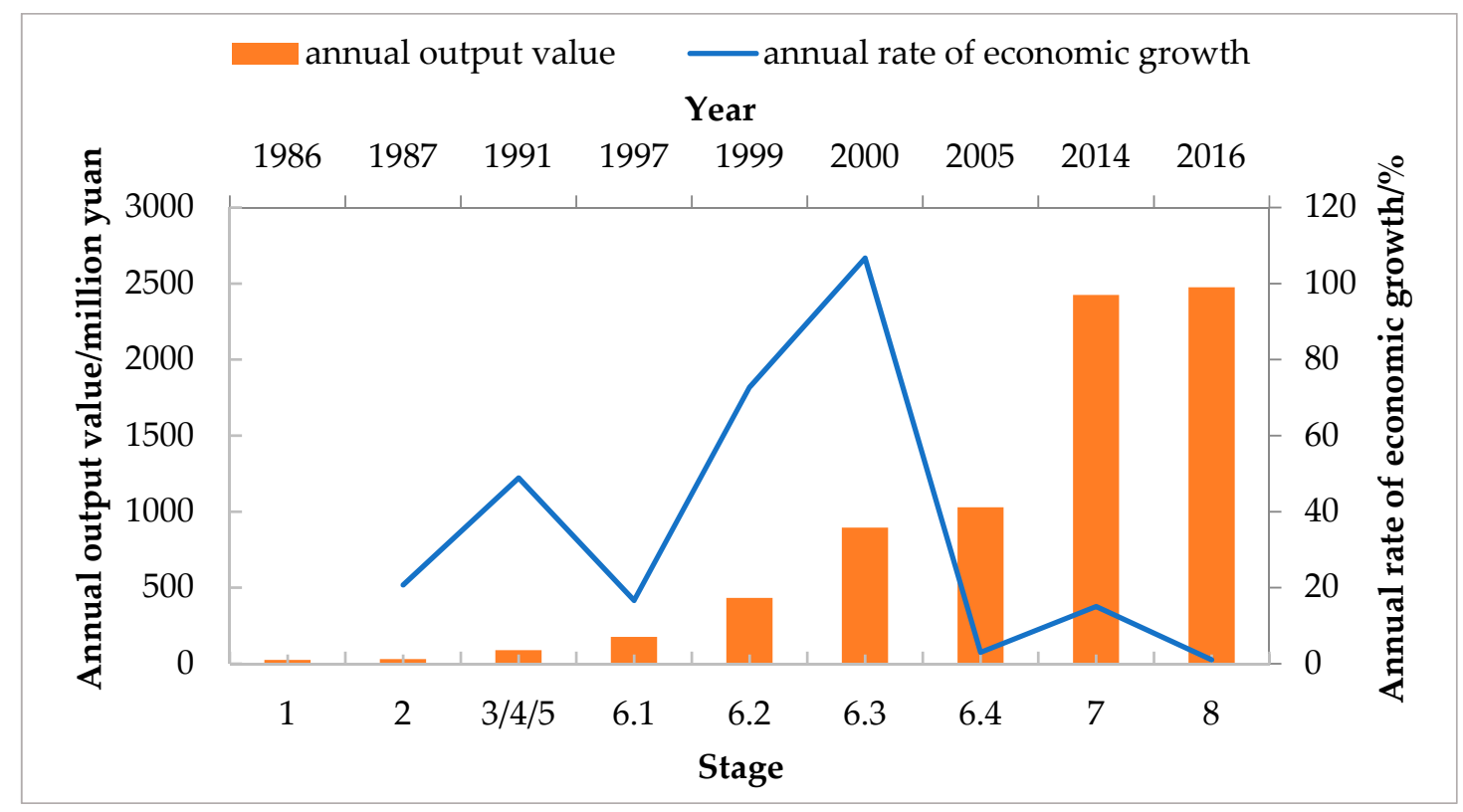

Figure 4. Annual output value and annual rate of economic growth.

The implementation of a green development strategy clearly did not contravene economic growth. At present, it is generally believed that the economic benefits introduced by the adoption of clean production methods are far inferior to those of general production methods, even if it were currently to be charged because of waste. However, the case enterprise showed that correct implementation of the green development strategy can provide better economic benefits.

A good economic foundation is the driving force for continued development, and is significant for sustaining the operations of enterprises. Therefore, economy is the basis for enterprises to consider economic returns when they shift their focus to implementing a green development strategy. Additionally, technologies that can utilize resources efficiently and reduce pollution must have better economy with increasing attention on environmental protection worldwide.

In this case, the enterprise gained increased economic benefits through the gradual evolution of the PSC process. Additionally, the production income was invested to improve the PSC process. Thus, it is necessary to form a virtuous circle in which economic benefits promote the development of greenness and green development creates more economic value in return.

\subsection{Analysis of the Resource Contribution}

For substance efficiency, as shown in Table 2, with the gradual progress of green evolution, the utilization rate of phosphorus in the PSC process presented an upward trend, rising from $89 \%$ to $97 \%$.

The main cyclic element is clearly sulfur, which is calculated as an example to analyze the element cycle index in the PSC process. As shown in Table 2, in stage 1, the element cycle index of sulfur was zero because there was no use of gypsum in the first stage. After a series of improvements, the element cycle index of sulfur reached approximately $93 \%$.

The increase in these two indicators was mainly due to the evolution progress, because the PSC process became more complete, increasing the reaction time and providing a more reasonable cyclic design.

Regarding resource productivity in the PSC process, the results showed that, with the gradual progress of the green evolution, the resource productivity of the enterprise basically showed an upward trend, from 354 yuan/t to 871 yuan/t, that is, the ability to use resources to create economic value gradually improved. This improvement was mainly due to the increasing utilization of elements and the range of reused waste. 
In brief, waste absorbance abilities should be considered while enterprises implement the green development strategy. Moreover, it is meaningful to use source control and substitution in manufacturing. Regarding the development of science and technology, enterprises are capable of considering the use of substitutes for production during their green evolution or green transition and improving their production processes, as well as reducing their waste from the source.

In the case enterprise, the waste that was generated by phosphate fertilizer production was used to manufacture sulfuric acid and the co-product cement, achieving the reuse of waste, saving resources, and protecting the environment. Besides, the PSC process offers a solution to solve the difficult problem of gypsum treatment, and the reusing of gypsum improves the resource utilization.

In addition, in order to improve the utilization rate of the resources, it would be useful to follow the 3R principle of circular economy. Recycling can allow a portion of the reactants that have not fully responded to re-enter the production process and improve the conversion rate of the reactants. Additionally, reuse can make full use of misplaced resources, which also improves the resource efficiency.

For example, in this case, phosphogypsum, generated by the production of phosphate fertilizer, was decomposed and calcined into cement clinker and $\mathrm{SO}_{2} \cdot \mathrm{SO}_{2}$ was then used to produce sulfuric acid, which was returned to manufacture phosphate fertilizer. During the evolution of the enterprise, waste materials, such as gypsum and waste residue, were reused and recycled, and the sulfuric acid recycling operations were achieved.

\subsection{Analysis of the Environmental Contribution}

As of 2015, China had reached a total of 3.78 billion tons of bulk industrial solid waste, of which approximately 187 million tons is the industrial by-product gypsum, mainly phosphogypsum, titanium gypsum, and desulfurization gypsum [50]. However, it is difficult for current technologies to effectively achieve complete and coordinated treatment of solid waste containing sulfur in China because of the large number of sources of sulfur-containing solid waste and complex and diverse ingredients [51]. All of these issues represent serious bottlenecks that limit the sustainable development of China's chemical, power, and smelting industries [49].

This research focused on the solid waste phosphogypsum, salt gypsum, titanium gypsum, fly ash, and slag, and calculated the integrated utilization of solid waste, which was defined as the output solid waste divided by the usage amount. The estimated results for this index are displayed in Table 2 . It is worth noting that the integrated utilization of solid waste exceeded $100 \%$ because the previously stored fly ash was also used in the cement production.

In addition to solid waste, waste gas cannot be ignored. For this enterprise, mainly $\mathrm{SO}_{2}$ and $\mathrm{NO}_{x}$ were contained in the waste gas, especially $\mathrm{SO}_{2}$. Excluding these gases, the greenhouse effect is currently receiving increasing attention.

The greenhouse effect is the process by which radiation from a planet's atmosphere warms the planet's surface to a temperature above what it would be without its atmosphere [52]. If a planet's atmosphere contains radiatively active gases (i.e., greenhouse gases), they will radiate energy in all directions. A portion of this radiation is directed towards the surface, warming it [53]. The intensity of the downward radiation, that is, the strength of the greenhouse effect, will depend on the atmosphere's temperature and on the amount of greenhouse gases contained in the atmosphere [54].

Therefore, $\mathrm{CO}_{2}$, which is an important component of greenhouse gases, has attracted much attention. The $\mathrm{SO}_{2}$ and $\mathrm{CO}_{2}$ emissions of billion-yuan industrial added value were selected to analyze the variation of environmental influences. The results are displayed in Table 2.

It is shown in Table 2 that $\mathrm{CO}_{2}$ emissions could be greatly reduced if the PSC process were used to produce cement because $\mathrm{CaSO}_{4}$ was used to replace $\mathrm{CaCO}_{3}$ as a raw material. The increasing use of gypsum and the increasing income were the main causes of the decline in $\mathrm{CO}_{2}$ emission of billion-yuan industrial added value during the green evolution. $\mathrm{SO}_{2}$ emission presents a trend like $\mathrm{CO}_{2}$ emission 
except in stage 1. Because income was increasing, the $\mathrm{SO}_{2}$ emission of billion-yuan industrial added value decreased during the green evolution.

It is shown from the case enterprise that it is important to insist on technological innovation for enterprises when they develop and improve green production methods. Currently, environmental protection has been a strong social demand for everyone. Thus, enterprises are forced to pay close attention to environmental issues during their development. Additionally, the ownership of a core production technology by enterprises is a foundation. To achieve the purpose of continuous improvement and development, enterprises should focus on technical innovation and try to improve the currently available technology, or evaluate the type of waste that can be handled by existing manufacturing processes and imitate previous findings to design new processes.

The enterprise in this case developed the PSC process. With the continuously optimized and improved PSC process, the enterprise combined new technology to produce titanium dioxide with the PCS process and established a systematic green production process that finally provided a variety of benefits.

\subsection{Analysis of the Energy Contribution}

Energy variation is evaluated by an index defined as the energy consumption of ten-thousand-yuan industrial added value. Energy variation can be used to evaluate the efficiency with which enterprises use energy in economic activities, and it can reflect the changes in economic structure and energy efficiency.

As is shown in Table 2, the energy consumption was reduced from 1.773 to $1.614 \mathrm{t}$.ten thousand yuan $^{-1}$ in stage 2 because of the PSC process, providing an efficient way to achieve energy circulation. However, with the expansion of productivity and the use of varieties of solid waste, energy consumption tended to increase gradually during stage 2 to 6.4. Energy consumption was reduced from 2.544 to $1.651 \mathrm{t}$.ten thousand yuan ${ }^{-1}$ in stage 7 because of the increasing economic income. In stage 8 , energy consumption increased due to the co-treatment of alkylated waste sulfuric acid.

As evident in Table 3, the energy index was the deficiency of the evaluation (score average 33), because the energy consumption of the case enterprise is about $305 \%$ of the national average. That is, for the case enterprise, energy contribution can be improved by the adjusting economic structure and strengthening energy conservation by the process transformation, such as increasing the production of high value-added products and the graded use of energy and waste heat recovery.

\section{Conclusions}

The GDD is a comprehensive index which is in line with the national green development strategy, and can evaluate the greenness of enterprises from economy, resource, environment, and energy aspects.

Moreover, from the calculation of the GDD, aspects that could be improved could be determined for further development. Additionally, different norms could display different aspects of enterprise achievements.

Through the calculation of the GDD, some experiences of green development in chemical enterprises can be summarized. First, resource recycling and improved resource utilization efficiency can be achieved through the symbiotic coupling of chemical processes and cross-industry chains. Then, the environment index can be improved by reducing pollutant emissions. Additionally, it is essential for enterprises to enhance the added value by extending the chemical industry chain and expanding the scale moderately. These features can be helpful for improving the economic index.

In addition, the GDD provides a method for enterprise groups to evaluate the subsidiary corporations that can assist groups to effectively manage and improve. At present, it is important to compare the degree of enterprise greenness and establish a standard for the enterprise. The GDD can make the comparison and establishment accessible and provide a means for macro-control.

Author Contributions: Conceptualization, Y.C.; Data curation, Y.C.; Formal analysis, Y.C.; Investigation, Y.C.; Project administration, S.H. and D.C.; Supervision, H.Z., S.B., and T.L.; Visualization, Y.C.; Writing - original draft, Y.C.; Writing - review \& editing, S.H. 
Funding: This study was funded by the National Key Research and Development Program of China, grant number 2018YFC1903801.

Acknowledgments: We acknowledge the work of past and present advisors and technical, research, and data management staff in supporting the data collection and providing the laboratory analyses for this project.

Conflicts of Interest: The authors declare no conflict of interest.

\section{References}

1. Cui, J.; Zhang, D.; Lv, Y.; Ding, M. Talking about the Present Situation of China's Coal Chemical Industry and the Development Trend of the 13th Five-Year Plan. Henan Chem. Ind. 2018, 35, 8-12.

2. Lin, H. Environmental status and development trend of the chemical industry. Chem. Eng. Des. Commun. 2018, 44, 195.

3. Fu, C.; Wang, F. Environmental Protection of Chemical Enterprises and Treatment of Three Wastes. Shandong Chem. Ind. 2017, 46, 181-182.

4. $\mathrm{Hu}, \mathrm{R} . ; \mathrm{Wu}, \mathrm{L}$. Analysis of the status quo of Chinese chemical enterprises. Chem. Enterp. Manag. 2018, 24, 4.

5. Anastas, P.T.; Warner, J.C. Principles of Green Chemistry. Sustain. Ind. 1998, 01, 29-56.

6. Dong, $X$. The current situation and development strategy of environmental protection in China's chemical industry. Chem. Eng. Des. Commun. 2018, 44, 188-208.

7. Zhe, L.; Yong, G.; Hung-Suck, P.; Huijuan, D.; Liang, D.; Tsuyoshi, F. An emergy-based hybrid method for assessing industrial symbiosis of an industrial park. J. Clean. Prod. 2016, 114, 132-140. [CrossRef]

8. Cheng, L. The significance, difficulties and safeguards of promoting green development under the new economic normal. MYKJ 2016, 9, 240.

9. Constable, D.J.C.; Curzons, A.D.; Cunningham, V.L. Metrics to 'green' chemistry-Which are the best? Green Chem. 2002, 4, 521-527. [CrossRef]

10. Jiménezgonzález, C.; Constable, D.J.; Ponder, C.S. Evaluating the "greenness" of chemical processes and products in the pharmaceutical industry-A green metrics primer. Chem. Soc. Rev. 2012, 41, 1485-1498. [CrossRef]

11. Sheldon, R.A. Green chemistry and resource efficiency: Towards a green economy. Green Chem. 2016, 18, 3180-3183. [CrossRef]

12. Marek, T.; Mariusz, M.; Agnieszka, G.U.; Jacek, N.N. Green Chemistry Metrics with Special Reference to Green Analytical Chemistry. Molecules 2015, 20, 10928-10946.

13. Tickner, J.A.; Becker, M. Mainstreaming green chemistry: The need for metrics. Curr. Opin. Green Sustain. Chem. 2016, 1, 1-4. [CrossRef]

14. Mustapha, M.A.; Manan, Z.A.; Wan Alwi, S.R. A new green index as an overall quantitative green performance indicator of a facility. Clean Technol. Environ. Policy 2016, 45, 1-11. [CrossRef]

15. Ga Uszka, A.; Migaszewski, Z.A.M.; Konieczka, P.; Nik, J.N. Analytical Eco-Scale for assessing the greenness of analytical procedures. Trends Anal. Chem. 2012, 37, 61-72. [CrossRef]

16. Sheldon, R.A. Metrics of Green Chemistry and Sustainability: Past, Present and Future. ACS Sustain. Chem. Eng. 2017, 6, 32-48. [CrossRef]

17. Jimenez-Gonzalez, C.; Ponder, C.S.; Broxterman, Q.B.; Manley, J.B. Using the Right Green Yardstick: Why Process Mass Intensity Is Used in the Pharmaceutical Industry To Drive More Sustainable Processes. Org. Process Res. Dev. 2011, 15, 912-917. [CrossRef]

18. Chen, X.; Qiao, L. Material Flow Analysis of China's Economic-Environment System. J. Natl. Resour. 2000, 15, 17-23.

19. Brunner, P.H.; Rechberger, H. Practical handbook of material flow analysis. Int. J. Life Cycle Assess. 2004, 9, 337-338. [CrossRef]

20. Shi, Y.; Yang, J.; Liu, J.; Chen, B.; Wang, R. Analysis of Research Methods of Material Metabolism in Eco-industrial Park Based on MFA. Acta Ecol. Sin. 2010, 30, 228-237.

21. Ramanathan, R. A note on the use of the analytic hierarchy process for environmental impact assessment. J. Environ. Manag. 2001, 63, 27-35. [CrossRef] [PubMed]

22. Handfield, R.; Walton, S.V.; Sroufe, R.; Melnyk, S.A. Applying environmental criteria to supplier assessment: A study in the application of the Analytical Hierarchy Process. Eur. J. Oper. Res. 2002, 141, 70-87. [CrossRef] 
23. Curzons, A.D.; Mortimer, D.N.; Constable, D.J.C.; Cunningham, V.L. So you think your process is green, how do you know?-Using principles of sustainability to determine what is green-A corporate perspective. Green Chem. 2001, 3, 1-6. [CrossRef]

24. Li, C. Construction and Application of Retrospective Evaluation Index System for Environmental Performance of Eco-industrial Demonstration Park. Master's Thesis, Shandong University, Jinan, China, 2014.

25. Zhao, T.; Yang, L.; Yin, Y. Comprehensive evaluation of eco-industrial park. Chin. Agric. Mech. 2009, 1, 35-38.

26. Deng, J. Research on Evaluation Index System and Evaluation Method of Eco-industrial Park. Master's Thesis, Xi'an University of Science and Technology, Xi'an, China, 2004.

27. Wu, X.; Wang, Y.; Liu, N.; Gao, Q.; Lu, G. Evaluation of Industrial Park Circular Economy Development Based on Ecological Efficiency Theory and TOPSIS Method. Chin. J. Ecol. 2008, 27, 2203-2208.

28. Gao, Y. Research on Evaluation Index System and Evaluation Method of Eco-industrial Park. Master's Thesis, Harbin Engineering University, Harbin, China, 2007.

29. Yang, T.; Ren, Y.; Shi, L.; Wang, G. The circular transformation of chemical industrial parks: An integrated evaluation framework and 20 cases in China. J. Clean. Prod. 2018, 196, 763-772. [CrossRef]

30. Axon, S.; James, D. The UN Sustainable Development Goals: How can sustainable chemistry contribute? A view from the chemical industry. Curr. Opin. Green Sustain. Chem. 2018, 13, 140-145. [CrossRef]

31. Qin, Y.; Li, M.; De, G.; Huang, L.; Yang, S.; Tan, Q.; Tan, Z.; Zhou, F. Research on Green Management Effect Evaluation of Power Generation Enterprises in China Based on Dynamic Hesitation and Improved Extreme Learning Machine. Processes 2019, 7, 474. [CrossRef]

32. Wang, B.; Wu, Y.; Zhao, J. Comprehensive evaluation on low-carbon development of coal enterprise groups. Environ. Sci. Pollut. Res. 2019, 26, 17939-17949. [CrossRef]

33. Han, Y.; Lu, Z.; Chen, S. A hybrid inconsistent sustainable chemical industry evaluation method. J. Ind. Manag. Optim. 2019, 15, 1225-1239. [CrossRef]

34. Guo, L. Research on Comprehensive Evaluation Method of Technology and Economy of Energy Supply System. In Proceedings of the 2018 4th International Conference on Environmental Science and Material Application, Xi'an, China, 15-16 December 2019; pp. 32206-32207.

35. Tao, S. Model of Green Evaluation Index of PetroChemical Enterprises by Consistency AHP; ICSP: Weihai, China, 2019; pp. 52008-52009.

36. Miao, Y.; Kang, R.; Chen, X. Level Evaluation of Ecological Sustainable Development of Chemical Enterprises. In Proceedings of the 2nd International Symposium on Resource Exploration and Environmental Science, Ordos, China, 28-29 April 2018; pp. 32004-32008.

37. Wang, L. Research on the Development Model of Regional Circular Economy. Ph.D. Thesis, Ocean University of China, Qingdao, China, 2005.

38. Ren, J.; Qian, F.; Liu, P. Regional resource output rate accounting method and empirical research. China Popul. Resour. Environ. 2017, 27, 152-154.

39. Qian, Y.; Li, H. Empirical Study on Zhejiang Province's Manufacturing Resource Output Rate. Zhejiang Stat. 2007, 2, 10-12.

40. Feng, Z. Resource output rate: An important indicator of green transformation. China Econ. Wkly. 2011, 14, 20-21.

41. Zhao, J. Analysis of the Survey of Regional Resource Output Rate in Taiyuan City. Technol. Innov. Product. 2013, 8, 17-19.

42. Lu, Z. How was the miracle created?-Report from Lubei Chemical Co., Ltd. Zhongguo Huagong 1996, $11,42-43$.

43. She, C. Research on Circular Economy Model of Lubei Chemical Industry Group-The Birth and Development of Legal Licensing System. Mod. Bus. Trade Ind. 2007, 3, 16-17.

44. Li, C.; Li, X.; Hou, M. Lubei Chemical: "Three Degrees" to Build an Eco-industrial Symbiosis System. China Economic Times, 8 August 2006; C2.

45. Liu, D.; Wang, Z. Lubei: Creating a circular economy model in the park. Chem. Enterp. Manag. 2008, 9, 13-14.

46. Lu, Z.; Wang, W. The Dream of Recycling with High-tech Round Resources-Recording the Road of Developing Circular Economy of Shandong Lubei Enterprise Group. Chem. Enterp. Manag. 2003, 1, 48-49.

47. Sun, J. Shandong Lubei Enterprise Group Corporation. Eng. Sci. 1999, 2, 95-96.

48. Sun, J. Shandong Lubei Enterprise Group Corporation. Sulphuric Acid Ind. 2014, 5, 75. 
49. Bao, S.; Gao, Q.; Zhang, H. Titanium white waste acid high efficiency and high value utilization industrial practice. Shandong Chem. Ind. 2014, 43, 117-120.

50. Li, B. Research on Industrial Waste Management Model and Its Resource Utilization Approach. Masters' Thesis, Chongqing University, Chongqing, China, 2003.

51. Deng, Q.; Wang, Q.; Huang, Q.; Wang, Q. Study on Optimization Model of Industrial Solid Waste Recycling. Metal. Mine 2010, 407, 171-174.

52. Chatterjee, D.K. Intergovernmental Panel on Climate Change; Springer: Dordrecht, The Netherlands, $2011 ;$ p. 57.

53. Haigh, E. The Earth's Biosphere: Evolution, Dynamics, and Change. Ann. Assoc. Am. Geogr. 2003, 93, 753-755.

54. Keinonen, T.; Kärkkäinen, S.; Kukkonen, J.; Vesala, P.; Hurri, A. What Is the Greenhouse Effect? Fifth Graders' Ideas. Int. J. Learn. 2009, 16, 415-430.

(C) 2019 by the authors. Licensee MDPI, Basel, Switzerland. This article is an open access article distributed under the terms and conditions of the Creative Commons Attribution (CC BY) license (http://creativecommons.org/licenses/by/4.0/). 